\title{
Surveillance \& Society \\ Off the Record? \\ Article Arrestee Concerns about the Manipulation, Modification, and Misrepresentation of Police Body-Worn Camera Footage
}

\section{Emmeline Taylor}

City, University of London, UK

Emmeline.Taylor@city.ac.uk

\section{Murray Lee}

University of Sydney, Australia

murray.lee@sydney.edu.au

\begin{abstract}
Police body-worn cameras (BWC) have become the latest technological device introduced to policing on a wave of panacean promises. Recent research has reported the perspectives of police officers, police management, and the general public, but there have been no studies examining the views of police arrestees. Remedying this significant omission, this article presents findings generated from interviews with 907 individuals shortly after their arrest. Overall, we report a strong in principle support for police body-worn cameras amongst this cohort, particularly if the cameras can be operated impartially. The findings are organised into a trilogy of prominent and interrelated concerns voiced by the police detainees, namely the potential for the manipulation, modification, and misrepresentation of events captured by police body-worn cameras. The findings are discussed in a broader context of the "new visibility" of police encounters and contribute much needed findings to understand the culturally specific ways in which different publics experience and respond to visual surveillance.
\end{abstract}

\section{Introduction}

In reference to the recent mass expansion in police use of body-worn cameras (BWC), Ariel et al. (2016a: 745) suggest "[ $\mathrm{t}]$ here is a world-wide uncontrolled social experiment taking place." Driven by a litany of high-profile incidents exposing police improprieties, particularly in the USA, police organisations have clamoured to issue frontline officers with BWC ostensibly in an attempt to placate tensions and improve police-citizen relations. This substantial investment of public monies has occurred in the absence of sufficient understanding of if, how, and why, the cameras alter police-citizen encounters, particularly at crucial points such as arrest. A small but growing number of randomised control trials (RCTs) have been conducted (see, for example, Ariel, Farrar, and Sutherland 2015; Ariel et al. 2016a; Braga et al. 2018; Hedberg, Katz, and Choate 2017; Jennings, Fridell, and Lynch 2014) that seek to establish the impact of $\mathrm{BWC}$ on a range of variables including police use of force and complaints against the police. However, these do not adequately investigate how the cameras are used by officers and, in turn, are perceived and understood by citizens. In addition to the RCTs, a corpus of research exists examining the views and experiences of police officers (for example, see Ellis, Jenkins, and Smith 2015; Gaub et al. 2016; Goetschel and Peha 2017; Headley, Guerette, and Shariati 2017; Jennings, Fridell, and Lynch 2014; Katz et al. 2014; Roy 2014; Sandhu 2017); law enforcement leadership (Smykla et al. 2016; Sandhu 2017), and public 
attitudes towards police BWC (Ellis, Jenkins, and Smith 2015; Maskaly et al. 2017; White, Gaub, and Todak 2018) (see reviews by Lum et al. 2015; Lum et al. 2019). Yet, the views of police arrestees have thus far not been attended to.

It has been recognised that "more research is needed on citizen behaviours and attitudes related to BWC" since this group has "received less attention than those of officers" (Lum et al. 2015: 19). In particular, the views of individuals encountering camera-wearing officers as a result of being placed under arrest are largely unknown (although see Newell, Gomez, and Guajardo 2017 on migrants' perceptions of BWC by Border Patrol agents). This paper explicates some hitherto unexplored complexities of BWC in an analysis of 907 interviews with police detainees undertaken shortly after arrest across four states in Australia. To our knowledge, the current study is the first to provide the views and experiences of individuals detained by police and, as such, this article provides empirical data to fill a substantial gap (see also Lee, Taylor, and Willis 2018; Taylor and Lee 2019). Furthermore, given the lack of uniformity in the use of body-worn cameras internationally, the study offers a vital insight into the culturally specific ways in which different publics experience surveillance cameras.

The article is organised into four main parts. The first section offers an overview of the emergence of police BWC, situating their advent in an historical trend culminating in what has been termed "the new visibility" era of policing (Brucato 2015; Goldsmith 2010; Yesil 2011) before reporting on empirical research regarding the impact and effect of police BWC, as well as studies seeking to elicit officer and public perceptions. The second section details the methodology used in the project before presenting the findings in the third section. Overall a high level of in-principle support was found for police BWC, if the cameras can be operated impartially. However, many participants were sceptical about the ability of BWC to capture footage and produce evidence that was neutral and without bias. The analysis is organised into a trilogy of prominent and interrelated concerns voiced by the police detainees, namely the potential for the manipulation, modification, and misrepresentation of events captured by police BWC. These categories synthesise multiple concerns held by arrestees relating to police capacity to curate and produce footage that would unduly incriminate them, whilst simultaneously exonerating the actions of officers. Far from neutral, many participants believed that the footage, irrespective of what it depicted, had the potential to be transmogrified and even doctored. The fourth and final section discusses the implications of these findings for the operational use of police BWC.

\section{Police Body-Worn Cameras: Emergence and Developments}

The first static surveillance camera is reputed to have been installed in Trafalgar Square in London in 1960 (Norris, McCahill, and Wood 2004). Since then, there have been multiple devices introduced, with bodyworn cameras becoming the latest in a cache of audiovisual technologies used by the police, including drones, dash cams, and redeployable cameras. Characteristic of these developments is that cameras have become increasingly mobile, in part due to advances in technology and longstanding frustrations associated with the ease of circumventing static cameras (Brucato 2015; Gill and Loveday 2003). Although police BWC have been in use for over a decade (for example, the UK Home Office reports first trialling them in 2006 as part of a Domestic Violence Enforcement Campaign [DVEC] [Police and Crime Standards Directorate 2007]), they have recently attracted significant attention, particularly in the USA. The "recent crescendo" (Martinot 2014: 52) in the number of unarmed black men being killed at the hands of police in the USA resulted in BWC being mooted as a potential restraint to racialised policing. Following the riots at Ferguson, Missouri (sparked by the death of Michael Brown, an unarmed black teenager, who was shot and killed in 2014 by a white police officer), the then president, Barack Obama, pledged funding to introduce BWC in all US states to try and tackle the "simmering distrust" between police and minority communities (cited in Holland and Edwards 2014). Whilst recent debates have clearly been dominated by events in the USA, it is important to recognise that the introduction of police BWC is an international development, albeit varied in its uptake. 
In Australia, the site of the present study, police BWC can be traced back to 2007 although as a result of the prohibitive cost and large size of the early BWC, investment in the technology only began in earnest several years later (Sapienza 2009). The nature of Australia's implementation of BWC makes it an appropriate site for research. For example, following the issuance of 2,200 body cameras to frontline officers, in addition to the five hundred initially trialled by Gold Coast and traffic police, it has been claimed that the state of Queensland possesses the largest number of BWC issued to any law enforcement agency in Australia and the fourth largest in the world (Brisbane Times 2016). The New South Wales (NSW) Police Force, one of the largest in the world, announced in 2015 that they had invested over $\$ 4$ million in BWC technology to rollout cameras to all frontline police officers following what was described as "very positive results" from trials (NSW Government 2014: 1). The accompanying media release attributed several "key benefits," including:

[C]hanges in behaviour of potential offenders by virtue of merely being recorded; providing police and members of the public with an independent and accurate recording of events; [and] reduction in frivolous claims against police for misconduct whilst undertaking their duties. (ibid.)

This excerpt outlines the presumed positive impact that cameras can have on the behaviour of individuals interacting with police officers and highlights the need to further understand the perceptions of members of the public, and, crucially, those being apprehended and/or arrested by police officers. In addition to the above, all other Australian states have also invested in police BWC. In 2014, the Northern Territory Police Force commenced a trial of forty-eight police BWC allocated to police officers in selected regions (Northern Territory Police 2015). Similarly, Tasmania police have been trialling BWC (Billings 2015), and, according to media reports, Victoria police are currently evaluating a trial of police BWC before mainstreaming the cameras (Victorian Government Solicitors Office 2015). In South Australia the state government committed $\$ 5.9$ million to roll out police BWC to all frontline police officers by mid-2019 with the SA Police Association supporting their implementation as "commonsense" (cited in Holderhead 2015). There have been reports of police officers using their own devices in the interim, with the Acting Police Ombudsman stating, "I have noticed that some police officers, upon their own initiative, have purchased their own cameras" (ibid.). As such, clearly there is considerable interest and investment in establishing BWC as an enduring feature of frontline policing across Australia. Furthermore, a recent review of the literature (Lum et al. 2019) found that of seventy studies examining police BWC, fifty-two (74\%) were conducted in US jurisdictions, thus highlighting the need for research located in other geographical areas.

\section{Existing Research on Police Body-Worn Cameras}

In parallel with the rapid uptake of police BWC, there has been an emerging literature examining various aspects of their operation, impact, and effectiveness. Initial RCT studies found largely positive impacts of the cameras suggesting that they reduce the prevalence of use of force by the police (Ariel, Farrar, and Sutherland 2015: 531; Braga et al. 2018; Henstock and Ariel 2017), reduce violence by the public (Police and Crime Standards Directorate 2007), and reduce complaints against police (Ariel, Farrar, and Sutherland 2015; Police and Crime Standards Directorate 2007; Katz et al. 2014; Rankin 2013). However, the encouraging early findings were soon contradicted by results from "one of the largest multi-site prospective randomised controlled trials (RCT) in the history of criminal justice research," which reported that police BWC led to increased assaults against officers and did not reduce police use of force (Ariel et al. 2016a). In a later publication, the authors of the study largely attributed the results to officer discretion to turn the cameras on and off at will (Ariel et al. 2016b; see also Taylor 2016).

In addition to the small body of RCT research, attempts have been made to understand the perspective of police officers (Ellis, Jenkins, and Smith 2015; Gaub et al. 2016; Goetschel and Peha 2017; Headley, Guerette, and Shariati 2017; Jennings, Fridell, and Lynch 2014; Katz et al. 2014; Roy 2014; Sandhu 2017); law enforcement leadership (Smykla et al. 2016; Sandhu 2017) and public attitudes towards police BWC (Ellis, Jenkins, and Smith 2015; Maskaly et al. 2017; White, Gaub, and Todak 2018). It would appear from 
empirical studies thus far conducted that the police largely welcome the implementation of BWC for multiple and varied reasons (Ellis, Jenkins, and Smith 2015; Jennings, Fridell, and Lynch 2014; Sandhu 2017) and that they become more positive over time (see, e.g., Fouche 2014). In the Mesa (AZ) Police Department (MPD 2013) study, officers were positive about the ability of the cameras to improve police professionalism, enhance the quality of evidence, and yield more accurate accounts of encounters. Similarly, Ellis, Jenkins, and Smith (2015) report from their survey on the Isle of Wight that police officers believed that the cameras would assist with gathering evidence which, in turn, would "increase the likelihood of conviction."

Studies of citizens' views largely report support for police BWC (see review by Lum et al. 2019). However, it should be recognised that they are often accompanied with high, possibly unrealistic, expectations regarding the impact that the cameras could have on police accountability and procedural justice. For example, in the findings from their public opinion survey on the Isle of Wight, Ellis, Jenkins, and Smith (2015: 1) reported an "overwhelmingly positive (84-96\%) public attitude toward police use of cameras" premised on a belief that they could assist with gathering evidence, identifying criminals, increasing convictions, improving training, and improving disciplinary procedures. Furthermore, it is important to recognise that such support may vary by socio-demographics. Although a key driver of BWC uptake is purported to be to soothe racial tensions, the Black Lives Matter movement, in conjunction with multiple NGOs, has voiced strong opposition to police BWC, viewing them as symptomatic of "the mass surveillance of Black communities" (cited in Lartey 2016). Black residents in Baltimore City voiced similar views. Kerrison, Cobbina, and Bender (2018) reported that, although their interviewees were generally supportive of more video footage of police activities, they were sceptical that they could improve police accountability.

Perceptions on the desirability and efficacy of police BWC will also be premised upon how they are used and the regulatory frameworks within which they are deployed. Illustrating the discretionary latitude in the USA on when to record, a report on police BWC in the Phoenix Police Department reported that "analysis of the camera meta-data indicated that only 13.2 to 42.2 percent of incidents were recorded" (Katz et al. 2014: 3). Similarly, a report by the Denver Office of the Independent Monitor (2014) found that numerous incidents where officers punched or used stun guns on suspects were not recorded; less than half of the forty-five use-of-force incidents involving on-duty officers were recorded because the cameras were either turned off or experienced technical problems. Notwithstanding the difficulties such variation generates for comparative evaluation in terms of ascertaining effectiveness, the lack of informed policy governing operational procedures potentially undermines claims that police BWC can increase accountability and simultaneously raises significant evidentiary challenges (Bakardjiev 2015). Furthermore, and importantly, research conducted by White, Todak, and Gaub (2017) highlighted that citizens are not always aware when they have encountered an officer wearing a body-worn camera, whether it is actively recording or not. A phone-based survey of people who had interacted with an officer wearing a body-worn camera revealed that just over one-quarter of respondents reported being aware of its presence (see also McClure et al. 2017). This finding severely undermines the methodological reliability of studies that aim to measure the impact of BWC on citizen behaviour by using assaults on officers, reports of resisting arrest, or reported officer injuries as proxies to measure the effect of the camera. If an individual is not aware of the camera, it cannot be presumed to have affected their behaviour.

\section{Methodology}

Established in 1999, the Drug Use Monitoring in Australia (DUMA) programme is a quarterly collection of criminal justice and drug use information from police detainees at multiple sites (police stations or watchhouses) across Australia. It is conducted in partnership between the Australian Institute of Criminology (AIC), State Police Services, and local researchers. Trained interviewers, independent of law enforcement, conduct voluntary interviews with police detainees in private interview rooms within ninety-six hours ${ }^{1}$ of

1 The ninety-six-hour timeframe is imposed by the DUMA methodology in order to allow sufficient time for the detainee to have engaged with the drug market (should they have chosen to) so as to limit skewing the findings of the 
arrest. Participants may have been arrested for any offence or breach of conditions, not just drug-related offences. The DUMA survey instrument comprises two components: a core questionnaire and a quarterly addendum. The core questionnaire collects demographic data and other information about each detainee's drug usage and history. An addendum to the DUMA instrument was used to interview police detainees about their views and experience of two types of surveillance technologies deployed for the purposes of crime control — closed circuit television cameras (CCTV) and police body-worn video cameras (BWC). This paper reports findings on police BWC only (see Gannoni et al. 2017 for full report).

The instrument comprises multiple interval questions relating to demographics, drug use, and lifestyle attributes. The addenda questions concerning police BWC were a mix of ordinal multi-category questions using flashcards, binary questions, and open-ended questions. Participants responded to multi-category items using a 5-point Likert-scale measuring their level of agreement on items associated with the use of police BWC and their impact, with 5 indicating "strongly agree" and 1 indicating "strongly disagree." The findings in this paper relate to the multi-category question, "It's a good idea for police to wear body-worn cameras" using a Likert scale, which was followed by the open-ended question, "Why do you think this?" In addition, two open-ended questions: "What do you think would be the best thing about police wearing cameras?" and "What do you think would be the worst thing about police wearing cameras?"- both of which elicited many responses that revealed the strength of the reservations that accompanied the positive reception of police BWC.

\section{Research Sites}

The interviews were conducted in two periods of 2015: during July to August, and October to November. In the third quarter of 2015, interviews were conducted at four sites-Adelaide (SA), Brisbane (Qld), Perth (WA), and Surry Hills (NSW). In the fourth quarter, all sites remained the same except Surry Hills, which was replaced with Bankstown, also NSW. Most respondents were in Brisbane ( $\mathrm{n}=357 ; 39.4 \%)$, followed by Perth ( $\mathrm{n}=302 ; 33.3 \%)$, and Adelaide $(\mathrm{n}=177 ; 19.5 \%)$.

These sites and jurisdictions represent some interesting characteristics of policing in Australia. The WA police force is responsible for policing the world's largest single police jurisdiction covering two and a half million square kilometres with a structure comprising two regions, eleven districts, and 157 police stations. The NSW police service is Australia's oldest police organisation and now the third largest police organisation in the English-speaking world. As outlined above, Queensland's investment in BWC represents the largest number of devices issued to any law enforcement agency in Australia and one of the highest in the world. These characteristics make multisite research across four jurisdictions particularly fruitful for explicating the socio-culturally nuanced way in which police BWC are viewed and experienced.

\section{Participant Characteristics}

Across the two quarters, a total of 1,753 police detainees were approached for interview; $1,108(63 \%)$ agreed to be interviewed and $645(37 \%)$ declined. A total of 1,108 detainees answered at least some of the DUMA main interview questions, and of these, 907 went on to answer questions from the addenda relating to police BWC. The following findings relate only to those 907 participants. The majority (83.4\%) of the respondents were male. On average the detainees were 32.65 years of age ( $\mathrm{SD}=10.45$ years) with the youngest respondent being 17 and the oldest being 79. Approximately one fifth (19.2\%) of respondents identified as Aboriginal or Torres Strait Islander (ATSI). The following section reports on the findings from the DUMA addenda. The gender and age at time of interview is provided for all quotes.

\section{Findings}

Three quarters ( $\mathrm{n}=688 / 907 ; 75.9 \%)$ of police detainees agreed or strongly agreed that it is a "good idea" for police officers to wear cameras. Perceptual ratings were very similar between male and females and those

larger survey, e.g., if a detainee reports that they have not used drugs in the days prior, it is not because they have been detained and unable to. It is also, in part, due to ethical considerations. 
identifying as indigenous or non-indigenous, and no significant mean differences were found. In terms of age, the older the police detainee, the more likely they were to strongly agree or agree that it is a good idea for police to wear body-worn cameras; $86 \%(n=89)$ of those aged 46+ strongly agree and agree compared with $70 \%(n=176)$ of those age 17 to 25 .

Detainees were asked, using open-ended responses, what they thought was the "best" thing about police BWC. Participants' responses indicated that the top best things about police BWC were evidence (34\%; $\mathrm{n}=261)$, accountability $(28 \% ; \mathrm{n}=212)$, and fairness $(19 \% ; \mathrm{n}=142)$. The multiple, nuanced, and complex reasons underpinning these positive responses are reported in more detail in Lee, Taylor, and Willis (2018) but were largely due to a belief amongst these participants that BWC could increase the accountability of police by providing a recording of police-citizen encounters. In turn, this was perceived to underscore greater fairness in the way that the police behaved towards those they were placing under arrest. However, the positive attributes were notably tempered by caveats about how they were operated and how the resulting footage would be used.

Detainees who reported police BWC were "not a good idea" were asked to expound upon their reasons for this viewpoint. Responses commonly related to the view that the cameras represented an invasion of privacy. This was particularly exacerbated if they believed that officers did or would not inform citizens or arrestees if they were wearing a camera and/or it was recording the interaction. There was also concern relating to recording inside people's homes where the expectation of privacy is heightened.

Asked what the "worst" thing about police BWC is, one in four detainees $(25 \% ; n=166)$ professed views that related to unfairness. Typical of these responses was the view that footage from police BWC could be manipulated or misused in various ways. For example, there were concerns relating to the officers' discretion regarding when to start and stop recording. The following analysis is divided into three prominent and interrelated concerns voiced by the police detainees: manipulation (the selective recording of events), modification (the editing of footage once recorded), and misrepresentation (the distortion of events as a result of the bias inherent in point-of-view cameras).

\section{Manipulation: The Selective Recording of Events}

As noted above, police BWC have been operated with considerable discretionary latitude. Initially this was requisite in early systems for several reasons including a limited battery life in early devices, concerns about retrievability, and the considerable data storage required prohibiting the continuous recording of entire shifts (Taylor 2016). However, there was notable concern amongst police detainees that this discretion opened avenues for the misuse of the cameras. Respondents believed that there was an intrinsic power imbalance, since the cameras were operated by the police, thus ensuring that citizen misbehaviours were routinely captured, but any police impropriety would not be. Such manipulation had reportedly been experienced by a few participants who stated that "they [the police] have stopped and started the cameras on me before" (Male, 28) and that it was convenient that the "camera 'doesn't work' the day you're being arrested" (Male, 26). In a similar vein, another individual stated, "If they [the police] have done wrong, the footage seems to vanish" (Male, 22). Many similar concerns about the ability of police officers to manipulate footage by selectively recording events were voiced as illustrated in these quotes:

[Police officers are] able to turn it on and off whenever they want to look good. (Male, 32)

They can still manipulate the data by turning the cameras on and off. (Female, 40)

It only shows their version - they can manipulate it by turning it off and on. (Female, 50)

Relatedly, some participants were concerned that unless all officers were wearing a camera there could be opportunities for events not to be recorded, as voiced by one individual: "If they're not all wearing cameras, 
the one with the camera could turn away whilst the other police officer is violent towards me" (Male, 33) (see Taylor 2016 for an example of this).

It was also stated by numerous participants that police officers might try to deliberately provoke individuals off-camera and then begin recording once the person in question began to react in a negative or aggressive way.

[The police] can edit and cut things out. [They] can influence the situation and make things look worse for the offender - they can provoke the offender. (Male, 25)

Sometimes the police make smartarse comments to provoke you, like when my children were taken away [they said] "you're not fit enough to look after dogs." That upset me and then the camera is turned on to show me upset. (Female, 25)

They [police] have an upper advantage - they can provoke you to behave in a certain way and then turn the camera on. (Male, 24)

It is important to note that the majority of BWC in operation have a pre-record buffer, usually between thirty seconds and two minutes, so that some contextual footage is captured before the activation of the camera. For other participants, provided the cameras were recording, the footage offered them some comfort that unacceptable behaviour on the part of the police was being recorded. As one Aboriginal detainee explained, the BWC "catches police doing wrong ... today the cop was wearing a camera and called me a "black fucker' in front of my son. Then he denied it" (Male, 37).

\section{Modification: Editing Footage after the Event}

Like the issues raised above regarding selective recording, there was also considerable concern that police officers were able to modify captured footage post hoc. As Goldsmith (2010: 921) has noted, "Not every picture tells a true story" due to the "the technical capabilities of the new media technologies (to re-write, manipulate, etc.)." The participants in the present study believed that this modification could be done in situ by deleting footage from the BWC device, or later when the officer was back at the police station, as illustrated in these interview excerpts.

They [police] shot me with a Taser and cut the footage out, there's no point if they're not going to use it. (Male, 42)

They [police] can come back to the station and alter the video image to suit themselves. (Female, 31)

Police may fiddle with video evidence. (Male, 28)

In order to be admissible in court adequate safeguards must be in place to protect the integrity of BWC footage. However, there have been recent reports that multiple camera models currently sold to law enforcement agencies have vulnerabilities that "would allow an attacker to download footage off a camera, edit things out or potentially make more intricate modifications, and then re-upload it, leaving no indication of the change" (Newman 2018). Furthermore, the recent high-profile allegation that followed an exchange between Donald Trump and CNN Chief White House Correspondent Jim Acosta, that footage was doctored so as to make it look as though Acosta struck a female aide when she tried to take the microphone from him, raises serious concerns about the reliability of footage emanating from even the highest of offices.

It is perhaps not surprising, given the sophisticated technological capacity to edit video, that the participants in the present study called into question the integrity of footage recorded on police BWC. Whether or not factual, there was a perception that police officers had control over the recorded images, being able to delete 
them at will. If police organisations are to effectively "sell" the BWC concept to the public, there is still considerable public relations work to be done in convincing some in the community that BWC footage is free from post hoc manipulation.

\section{Misrepresentation and Distortion of Events}

There is a prevailing view that camera footage provides a neutral and objective account of events. As Yesil (2011: 285) states: "They are generally conceptualized as instruments that we can believe in as neutral recorders of truth and reality, and stand as symbols of neutral vision and transparency mostly because they serve as 'nonhuman witnesses' in the sense that human capacities are irrelevant to their operation." Challenging this perception, a body of research is emerging that raises doubts about the presumed evidentiary capacity of video and photographic imagery in court (Bakardjiev 2015; Edmond et al. 2009). A recurrent theme emerging from our data was that police detainees contested the presumed impartiality of recorded footage taken from BWC and therefore its suitability as evidence in court. For example, related to the above points, concerns were raised regarding the deliberate misrepresentation of events by selectively choosing footage to show in court proceedings that obscured the full context and sequence of events:

[The footage] can be incriminating, or it could be used out of context. For example, only showing certain parts of an event captured on camera, not the whole thing. (Female, 23)

The evidence may be used against you in a way you didn't expect-words taken out of context by not showing what happened before and after. I didn't know they filmed my arrest until I heard them talking about turning off the camera afterwards. (Male, 25)

There is a long-established body of research illustrating an implicit "camera view bias" whereby viewers are inclined to interpret footage from the perspective of the camera or the person wearing the camera: "When video allows us to look through someone's eyes, we tend to adopt an interpretation that favors that person" (Stoughton cited in Williams et al. 2016). ${ }^{2}$ Lassiter et al. (2005: 28) have highlighted the "robust and pervasive" biasing effect of camera perspective in studies of videotaped confessions. They point to the "reality" gleaned from multiple studies that if a camera is focused solely on a suspect confessing during an interrogation it influences the perceived likelihood of guilt and sentencing recommendations (see also Lassiter and Irvine 1986 in relation to police interrogations). Similarly, the positioning of the camera and its field of vision has been found to impact the interpretation of events in relation to dashboard cameras (Kahan, Hoffman, and Braman 2009).

Regarding police BWC specifically, this has been demonstrated through simulations of police-public encounters that highlight the degree to which footage is subjectively interpreted and usually to the detriment of the citizen (Boivin et al. 2017; Williams et al. 2016). For example, in a study by Boivin et al. (2017), participants (undergraduate students and police candidates) viewed one of two videos showing a fictional police intervention during which lethal force was used against an individual. The incident was filmed from both a body-worn camera and a wall-mounted surveillance camera. The authors reported significant camera perspective bias amongst police candidates whose opinions on the appropriateness of the intervention were significantly different when the footage from the BWC was viewed compared to the footage from the fixed camera.

\section{Conclusion}

The participants in this Australia-based study, while seeing BWC largely as a "good thing," were concerned about the neutrality of footage that was captured and managed by the police. Their concerns have been catalogued into three broad and interrelated categories in order to highlight the significant caveats that

${ }^{2}$ At the time of writing Seth Stoughton is an Associate Professor at the University of South Carolina School of Law. 
accompany an otherwise largely positive reception of police BWC. The findings provide some nuances to the existing discourse, particularly that emanating from the USA, that depicts the vast majority of the public as welcoming of, if not demanding that, officers wear cameras in an attempt to curb police improprieties, race-based traffic stops, and excessive use of force. The findings presented in the current article highlight the importance of the methodological approach when attempting to elicit opinions on complex social issues. It is notable that surveys of citizen and community attitudes towards police BWC typically return positive results (see review by Lum et al. 2019) in the same way that the Likert-scale closed question did in the present study. Yet those studies that use additional methodologies such as interviews, including our own, comprising open-ended exploratory questions, reveal significant caveats to this assertion (e.g., Kerrison, Cobbina, and Bender 2018). It is important to be attuned to the multiple concerns raised by those individuals who are most likely to encounter camera-wearing police officers, if procedural justice is to be achieved and police legitimacy maintained.

Perhaps not surprisingly, there is considerable scepticism regarding how police BWC will affect policing encounters. Due to a range of reasons (including camera view bias, the discretion to turn the camera on and off, and choosing what footage is marked as "evidence"), there is a significant power imbalance with officer use of BWC. The police officer essentially becomes the producer of the "action." This runs the risk of the camera being viewed as another means to gather evidence against citizens, rather than an instrument for enhancing accountability (see also Lee, Taylor, and Willis 2018). Illustrating this, in an insightful study into how BWC is used in court, Merola et al. (2016) found that in nearly all relevant cases $(93 \%)$ the footage was used to prosecute citizens (rather than to support the defence or to prosecute police). So whilst the saturation of images derived from multiple types of surveillance cameras (e.g., dashcams, drones, wearables, and so on) as well as public mobile phones has ushered in a "new visibility" of the police (Brucato 2015; Goldsmith 2010; Yesil 2011), the imagery is still filtered through the organisational and professional vision of criminal justice agencies.

The corpus of research is certainly growing regarding the impact and effectiveness of BWC. However, it is still largely undetermined whether the cameras can deliver the high expectations bestowed upon them by the range of stakeholders. As Ariel et al. (2016a: 747) assert, "A handful of novel experiments provide insufficient evidence to justify the billions of public funds being spent globally on police body-worn technology." There have now been in the region of seventy studies focusing on police BWC (Lum et al. 2019), but given the multiplicity of ways in which they are deployed, the nuanced operational and procedural guidelines within which they operate, and the variance in the technology used, ${ }^{3}$ a lack of understanding regarding impact and effect endures.

\section{References}

Ariel, Barak, Tony Farrar, and Alex Sutherland. 2015. The Effect of Police Body-Worn Cameras on Use of Force and Citizens' Complaints Against the Police: A Randomized Controlled Trial. Journal of Quantitative Criminology 31 (3): $509-35$.

Ariel, Barak, Alex Sutherland, Darren Henstock, Josh Young, Paul Drover, Jayne Sykes, Simon Megicks, and Ryan Henderson. 2016a. Wearing Body Cameras Increases Assaults Against Officers and Does Not Reduce Police Use of Force: Results from a Global Multi-Site Experiment. European Journal of Criminology 13 (6): 744-55.

Ariel, Barak, Alex Sutherland, Darren Henstock, Josh Young, Paul Drover, Jayne Sykes, Simon Megicks, and Ryan Henderson. 2016b. Report: Increases in Police Use of Force in the Presence of Body-Worn Cameras Are Driven by Officer Discretion: A Protocol-Based Subgroup Analysis of Ten Randomized Experiments. Journal of Experimental Criminology 12 (3): $453-63$.

Bakardjiev, David K. 2015. Officer Body-Worn Cameras: Capturing Objective Evidence with Quality Technology and Focused Policies. Jurimetrics 56 (1): 79-112.

Billings, Patrick. 2015. Push for Police to Wear Body Cameras. Examiner (AU), May $20,2015$. http://www.examiner.com.au/story/3093142/push-for-police-to-wear-body-cameras/ [accessed September 27, 2016 ].

3 The National Institute of Justice (NIJ 2014) published a market report that examined the features of eighteen different models of body-worn cameras and covered varying features, such as positioning of camera (on chest, overear, attached to glasses, and so on), tracking features such as GPS, evidentiary safeguards, and time and date stamping of footage. There is even variation within forces. For example, Northamptonshire Police claims to operationally use ten different makes and/or models of camera (Spencer and Cheshire 2018). 
Boivin, Rémi, Annie Gendron, Camille Faubert, and Bruno Poulin. 2017. The Body-Worn Camera Perspective Bias. Journal of Experimental Criminology 13 (1): 125-42.

Braga, Anthony, William H. Sousa, James R. Coldren, and Denise Rodriguez. 2018. The Effects of Body-Worn Cameras on Police Activity and Police-Citizen Encounters: A Randomised Control Trial. Journal of Criminal Law and Criminology 108 (3): 511-38.

Brisbane Times. 2016. Queensland Police Get 2200 More Body-Worn Cameras. Brisbane Times (AU) July $21,2016$. https://www.brisbanetimes.com.au/national/queensland/queensland-police-get-2200-more-bodyworn-cameras-20160721gqai35.html [accessed July 9, 2019].

Brucato, Ben. 2015. Policing Made Visible: Mobile Technologies and the Importance of Point of View. Surveillance \& Society $13(3 / 4): 455-73$.

Denver Office of the Independent Monitor. 2014. 2014 Annual Report. https://extras.denverpost.com/Denver Monitor 2014 Annual Report.pdf [accessed December 18, 2018].

Edmond, Gary, Katherine Biber, Richard Kemp, and Glen Porter. 2009. Law's Looking Glass: Expert Identification Evidence Derived from Photographic and Video Images. Current Issues in Criminal Justice 20 (3): 337-77.

Ellis, Tom, Craig Jenkins, and Paul Smith. 2015. Evaluation of the Introduction of Personal Issue Body Worn Video Cameras (Operation Hyperion) on the Isle of Wight: Final Report to Hampshire Constabulary. Portsmouth, UK: University of Portsmouth.

Fouche, Adam. 2014. Officer Attitudes on Deployment of Body-Worn Cameras in the University of Georgia Police Department Patrol Division. Campus Law Enforcement Journal 44: 21-28.

Gannoni, Alexandra, Matthew Willis, Emmeline Taylor, and Murray Lee. 2017. Surveillance Technologies and Crime Control: Understanding Police Detainees' Perspectives on Police Body-Worn Video (BWV) and CCTV Cameras (CRG 31/14-15). Canberra, AU: Criminology Research Advisory Council.

Gaub, Janne E., David E. Choate, Natalie Todak, Charles N. Katz, and Michael D. White. 2016. Officer Perceptions of Body-Worn Cameras Before and After Deployment: A Study of Three Departments. Police Quarterly 19: 275-302.

Gill, Martin, and Karryn Loveday. 2003. What Do Offenders Think About CCTV? Crime Prevention and Community Safety: An International Journal 5 (3): 17-25.

Goetschel, Max, and Jon M. Peha. 2017. Police Perceptions of Body-Worn Cameras. American Journal of Criminal Justice 42: 698-726.

Goldsmith, Andrew J. 2010. Policing's New Visibility. British Journal of Criminology 50 (5): 914-34.

Headley, Andrea. M., Rob T. Guerette, and Auzeen Shariati. 2017. A Field Experiment of the Impact of Body-Worn Cameras (BWCs) on Police Officer Behavior and Perceptions. Journal of Criminal Justice 53: 102-09.

Hedberg, Eric C., Charles M. Katz, and David E. Choate. 2017. Body-Worn Cameras and Citizen Interactions with Police Officers: Estimating Plausible Effects Given Varying Compliance Levels. Justice Quarterly 34 (4): 627-51.

Henstock, Darren, and Barack Ariel. 2017. Testing the Effects of Police Body-Worn Cameras on Use of Force During Arrests: A Randomized Controlled Trial in a Large British Police Force. European Journal of Criminology 14: 720-50.

Holderhead, Simon. 2015. Police Buying Video Cameras for Occupational Safety Amid Ownership Concern Over Vision as They're Not Official Issue. Advertiser, November 7, 2015. http://www.adelaidenow.com.au/news/south-australia/police-buyingvideo-cameras-for-occupational-safety-amid-ownership-concern-over-vision-as-theyre-not-official-issue/newsstory/5f11b48ebbe781793cf9d9b42ecc3d44 [accessedSeptember 27, 2016].

Holland, Steve, and Julia Edwards. 2014. Obama Vows to Address 'Simmering Distrust' Between Police, Minorities. Reuters, December 2, 2014. https://www.reuters.com/article/us-usa-missouri-shooting-obama/obama-vows-to-address-simmeringdistrust-between-police-minorities-idUSKCN0JF2ZH20141202 [accessed: September 10, 2018].

Jennings, Wesley G., Lorie A. Fridell, and Mathew D. Lynch. 2014. Cops and Cameras: Officer Perceptions of the Use of BodyWorn Cameras in Law Enforcement. Journal of Criminal Justice 42: 549-56.

Kahan, Dan M., David A. Hoffman, and Donald Braman. 2009. Whose Eyes Are You Going to Believe? Scott v. Harris and the Perils of Cognitive Illiberalism. Harvard Law Review 122 (3): 837-906.

Katz, Charles M., David E. Choate, Justin R. Ready, and Lidia Nuňo. 2014. Evaluating the Impact of Officer Worn Body Cameras in the Phoenix Police Department. Phoenix, AZ: Center for Violence Prevention \& Community Safety, Arizona State University.

Kerrison, Erin M., Jennifer Cobbina, and Kimberly Bender. 2018. Stop-Gaps, Lip Service, and the Perceived Futility of Body-Worn Police Officer Cameras in Baltimore City. Journal of Ethnic \& Cultural Diversity in Social Work 27: 271-88.

Lartey, Jamiles. 2016. Coalition of Activists Affiliated with Black Lives Matter Outline Policy Agenda. Guardian, August 2, 2016. https://www.theguardian.com/us-news/2016/aug/01/black-lives-matter-release-policy-statement [accessed September 27, 2016].

Lassiter, G. Daniel, and Audrey A. Irvine. 1986. Videotaped Confessions: The Impact of Camera Point of View on Judgments of Coercion. Journal of Applied Social Psychology 16 (3): 268-76.

Lassiter, G. Daniel, Patrick J. Munhall, Ian P. Berger, Paul E. Weiland, Ian M. Handley, and Andrew L. Geers. 2005. Attributional Complexity and the Camera Perspective Bias in Videotaped Confessions. Basic and Applied Social Psychology 27 (1): $27-$ 35.

Lee, Murray, Emmeline Taylor, and Matthew Willis. 2018. Being Held to Account: Detainees' Perceptions of Police Body-Worn Cameras. Australian \& New Zealand Journal of Criminology 52 (2): 174-92.

Lum, Cynthia, Christopher Koper, Linda Merola, Amber Scherer, and Amanda Reioux. 2015. Existing and Ongoing Body Worn Camera Research: Knowledge Gaps and Opportunities. Report for the Laura and John Arnold Foundation. Fairfax, VA: Center for Evidence-Based Crime Policy, George Mason University. 
Lum, Cynthia, Megan Stoltz, Christopher Koper, and Amber Scherer. 2019. Research on Body-Worn Cameras: What We Know, What We Need to Know. Criminology and Public Policy 18 (1): 93-118.

Martinot, Steve. 2014. On the Epidemic of Police Killings. Social Justice 39 (4): 52-75.

Maskaly, Jon, Christopher Donner, Wesley G. Jennings, Barak Ariel, and Alex Sutherland. 2017. The Effects of Body-Worn Cameras (BWCs) on Police and Citizen Outcomes: A State-of-the-Art Review. Policing: An International Journal of Police Strategies \& Management 40: 672-88.

McClure, David, Nancy La Vigne, Mathew Lynch, Laura Golian, Daviel Lawrence, and Aili Malm. 2017. How Body Cameras Affect Community Members' Perceptions of Police: Results from a Randomized Controlled Trial of One Agency's Pilot. Washington, DC: Justice Policy Center, Urban Institute. urban.org/sites/default/files/publication/91331/2001307-how-bodycameras-affect-community-members-perceptions-of-police_1.pdf [accessed November 12, 2018].

Merola, Linda, Cynthia Lum, Christopher S. Koper, and Amber Scherer. 2016. Body Worn Cameras and the Courts: A National Survey of State Prosecutors (Report for the Laura and John Arnold Foundation). Fairfax, VA: Center for Evidence-Based Crime Policy, George Mason University.

Mesa Police Department. 2013. On-Officer Body Camera System: Program Evaluation and Recommendations, Mesa, AZ: Mesa Police Department.

Neuendorf, Kimberly A. 2002. The Content Analysis Guidebook. Thousand Oaks, CA: Sage.

Newell, Bryce C., Ricardo Gomez, and Verónica E. Guajardo. 2017. Sensors, Cameras, and the New 'Normal' in Clandestine Migration: How Undocumented Migrants Experience Surveillance at the U.S.-Mexico Border. Surveillance \& Society 15 (1): $21-41$.

Newman, Lily H. 2018. Police Bodycams Can Be Hacked to Doctor Footage. Wired, August $11,2018$. https://www.wired.com/story/police-body-camera-vulnerabilities/ [accessed December, 2018].

NIJ (US National Institute of Justice). 2014. Body-Worn Cameras for Criminal Justice: Market Survey. https://www.justnet.org/pdf/Body-Worn-Camera-Market-Survey-508.pdf [accessed September 27, 2016].

Norris, Clive, Mike McCahill, and David Wood. 2004. Editorial: The Growth of CCTV: A Global Perspective on the International Diffusion of Video Surveillance in Publicly Accessible Space. Surveillance \& Society 2 (2/3): 110-35.

Northern Territory Police. 2015. Body Worn Video Trial. http://www.pfes.nt.gov.au/Police/Community-safety/Body-worn-videotrial.aspx [accessed September 27, 2016].

NSW (New South Wales) Government. 2014. Continued Investment in Technology for Frontline Police. Media Release. https://www.emergency.nsw.gov.au/media-releases/2014/continued-investment-in-technology-for-frontline-police.html [accessed September 27, 2016].

Pelfrey, William V., and Steven Keener. 2016. Police Body-Worn Cameras: A Mixed Method Approach Assessing Perceptions of Efficacy. Policing: An International Journal of Police Strategies \& Management 39 (3): 491-506.

Pepinsky, Harold E. 1984. Better Living Through Police Discretion. Law and Contemporary Problems 47 (4): $249-67$.

Police and Crime Standards Directorate. 2007. Lessons Learned from the Domestic Violence Enforcement Campaigns 2006. London: Home Office.

Rankin, H. 2013. End of Program Evaluation and Recommendations: On-Officer Body Camera System. Mesa, AZ: Mesa Police Department.

Roy, Allyson. 2014. On-Officer Video Cameras: Examining the Effects of Police Department Policy and Assignment on Camera Use and Activation. Master's thesis. Tempe, AZ: Arizona State University.

Sapienza, Joseph. 2009. Union Supports Body-Worn Cameras for Police. WA Today, March $20,2009$. http://www.watoday.com.au/wa-news/union-supports-bodyworn-cameras-for-police-20090319-92zd.html.

Sandhu, Ajay. 2017. 'I'm Glad That Was On Camera': A Case Study of Police Officers' Perceptions of Cameras. Policing \& Society 29 (2): $223-35$.

Smykla, John Ortiz, Matthew S. Crow, Vaughn J. Crichlow, and Jamie A. Snyder. 2016. Police Body-Worn Cameras: Perceptions of Law Enforcement Leadership. American Journal of Criminal Justice 41: 424-443.

Spencer, David, and Richard Cheshire. 2018. Ten Years of BodyWorn Video in Northamptonshire Police. Policing 12(1): 116-19.

Stenning, Philip. 2009. Discretion. In The SAGE Dictionary of Policing, edited by Alison Wakefield and Jenny Fleming, 85. London: Sage.

Taylor, Emmeline. 2016. Lights, Camera, Redaction... Police Body-Worn Cameras: Autonomy, Discretion and Accountability. Surveillance \& Society 14 (1): 128-32.

Taylor, Emmeline, and Murray Lee. 2019. Points of View: Arrestees' Perspectives on Police Body-Worn Cameras and Their Perceived Impact on Police-Citizen Interactions. British Journal of Criminology 59 (4): 958-78.

White, Michael D., Natalie Todak, and Janne E. Gaub. 2017. Assessing Citizen Perceptions of Body-Worn Cameras After Encounters with Police. Policing: An International Journal of Police Strategies and Management 40 (4): 689-703.

White, Michael D., Janne E. Gaub, and Natalie Todak. 2018. Exploring the Potential for Body-Worn Cameras to Reduce Violence in Police-Citizen Encounters. Policing: A Journal of Policy and Practice 12: 66-76.

Williams, Timothy, James Thomas, Samuel Jacoby, and Damien Cave. 2016. Police Body Cameras: What Do You See? New York Times, April 1, 2016. http://www.nytimes.com/interactive/2016/04/01/us/policebodycam-video.html?_r=0 [accessed September 27, 2016).

Yesil, Bilge. 2011. Recording and Reporting: Camera Phones, User-Generated Images and Surveillance. In ICTs for Mobile and Ubiquitous Urban Infrastructures: Surveillance, Locative Media, and Global Networks, edited by Rodrigo Jose Firmino, Fabio Duarte, and Clovis Ultramari, 272-93. Hershey, PA: IGI Global. 